\title{
Preparation of Niobium Nitride Films by CVD
}

\author{
Hiroshi FUNAKUBO, Nobuo KIEDA, Nobuyasu MIZUTANI \\ and Masanori KATO \\ (Department of Inorganic Materials, Faculty of Engineering, Tokyo Institute of Technology \\ 12-1, O-okayama 2-chome, Meguro-ku, Tokyo 152
}

\section{CVD 法による窒化ニオブ薄膜の合成}

舟寉 浩・木枝暢夫・水谷惟恭・加藤誠 軌

(東京工業大学 工学部 無機材料工学科)

\begin{abstract}
Niobium nitride films were deposited on fused silica substrates by the CVD process using reactant gas mixtures of $\mathrm{NbCl}_{5}, \mathrm{~N}_{2}, \mathrm{H}_{2}$ and $\mathrm{Ar}$ at a deposition temperature from $700^{\circ}$ to $1100^{\circ} \mathrm{C}$. The effects of deposition parameters on the film properties were investigated, and the deposition mechanism was discussed. Two regions with different rate-determining steps were found under the experimental conditions studied. At $1000^{\circ} \mathrm{C}$ and at a total gas flow rate from 1000 to $4000 \mathrm{ml} / \mathrm{min}$, the deposition rate was controlled by the mass transport in the gas phase, and the nitrogen content in the deposits increased with increasing deposition temperature and increasing mole ratio of $\mathrm{N}_{2}$ to $\mathrm{NbCl}_{5}$.

[Received July 15, 1986]
\end{abstract}

Key-words : Niobium nitride, CVD, Rate-determining step, $\mathrm{NbCl}_{5}-\mathrm{N}_{2}-\mathrm{H}_{2}$ system

\section{Introduction}

The chemical vapor deposition (CVD) is an effective method for forming films with high purity and density. However, the deposition process is so complex that it is necessary to control many experimental parameters in order to produce films with required properties.

In this study, niobium nitride films were prepared by the CVD process using the reactant gas mixture of $\mathrm{NbCl}_{5}, \mathrm{~N}_{2}, \mathrm{H}_{2}$ and Ar. In niobiumnitrogen system, the presence of seven different nitride phases $\left(\beta-\mathrm{Nb}_{2} \mathrm{~N}, \quad \gamma-\mathrm{Nb}_{4} \mathrm{~N}_{3}, \delta\right.$ - $\mathrm{NbN}, \quad \delta^{\prime}$ $\mathrm{NbN}, \varepsilon-\mathrm{NbN}, \mathrm{Nb}_{5} \mathrm{~N}_{6}$ and $\mathrm{Nb}_{4} \mathrm{~N}_{5}$ ) and a terminal solid solution $\left(\alpha-\mathrm{NbN}_{x}\right)$ have been reported ${ }^{11-3)}$. They are refractory compounds with extreme hardness, high chemical stabilities and high electrical conductivities. In these phases, $\delta$ - $\mathrm{NbN}$ with $\mathrm{NaCl}$ type structure is known to have considerably high superconducting transition temperature. Thus, the thin films of these compounds have potential applications as superconducting, electronic and corrosion-resistant materials.

A few studies have been done on the niobium nitride films by the CVD process ${ }^{4)-7}$. Takahashi et al. ${ }^{7)}$ synthesized niobium nitride films in the temperature range from $1100^{\circ}$ to $1400^{\circ} \mathrm{C}$ and in the $\mathrm{NbCl}_{5}-\mathrm{N}_{2}-\mathrm{H}_{2}$ system on graphite substrates.

The objectives of the present work are to investigate the growth parameters affecting the deposition process of niobium nitride by the CVD process in the temperature range from $700^{\circ}$ to $1100^{\circ} \mathrm{C}$ and to elucidate the deposition mechanisms.

\section{Experimental}

The schematic diagram of the CVD apparatus is shown in Fig. 1. The horizontal alumina reaction tube was composed of three different temperature zones heated by independently controlled electric furnaces. The "A" zone was to generate $\mathrm{NbCl}_{5}$ vapor by heating $\mathrm{NbCl}_{5}$ powder in a molybdenum container, and the concentration of the $\mathrm{NbCl}_{5}$ vapor in gas phase was controlled by changing the temperature of "A" zone. The amount of evapo-

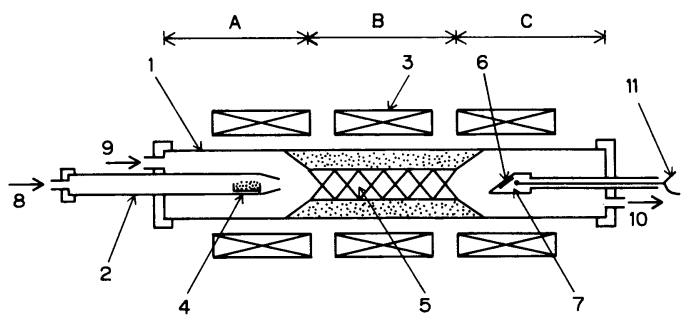

Fig. 1. Schematic diagram of the CVD apparatus (1: alumina tube, $2:$ fused silica tube, $3:$ electric furnace, $4: \mathrm{NbCl}_{5}$ powder, $5:$ static mixer, $6:$ substrate, $7:$ graphite holder, $8:$ carrier Ar gas, $9:$ gas mixture of $\mathrm{N}_{2}, \mathrm{H}_{2}$, and Ar, $10:$ gas outlet, $11:$ thermocouple). 
rated $\mathrm{NbCl}_{5}$ was calculated from the weight change of the $\mathrm{NbCl}_{5}$ powder before and after experiment. The $\mathrm{NbCl}_{5}$ vapor was carried by deoxygenized Ar gas to the gas mixer "B" where the $\mathrm{NbCl}_{5}$ vapor was mixed with the gas mixture of $\mathrm{H}_{2}, \mathrm{~N}_{2}$ and Ar. These gasses were purified by titanium nitride sponge heated about $800^{\circ} \mathrm{C}$ before mixing, and the flow rate of each gas was controlled within $5 \%$ by a precise needle valve. The " $\mathrm{C}$ " zone was the reaction chamber. A fused silica substrate $(10 \mathrm{~mm} \times 10 \mathrm{~mm} \times 2 \mathrm{~mm})$ was placed on a graphite holder so that the surface of the substrate was inclined by $30^{\circ}$ to the gas flow direction. Its temperature was measured by a $\mathrm{Pt}-\mathrm{Pt} \cdot \mathrm{Rh}$ thermocouple which was inserted into the specimen holder.

The formation of $\mathrm{NbN}_{x}$ is considered to proceed as follows:

$$
\begin{array}{r}
\mathrm{NbCl}_{5}(\mathrm{~g})+x / 2 \mathrm{~N}_{2}(\mathrm{~g})+5 / 2 \mathrm{H}_{2}(\mathrm{~g}) \\
\mathrm{Ar}
\end{array} \mathrm{NbN}_{x}(\mathrm{~s})+5 \mathrm{HCl}(\mathrm{g})
$$

The deposited phase was identified by XRD (Philips PW-1700). The microstructures of the surface and the fractured surface of the deposits were observed by SEM (JEOL JSM-T 200).

\section{Result and discussion}

\subsection{Deposition rate and microstructure}

Figure 2 shows the effect of the deposition temperature on the deposition rate which was calculated from the weight change of the deposit produced on the substrate in 30 minutes. It has been confirmed here that the weight of the deposit

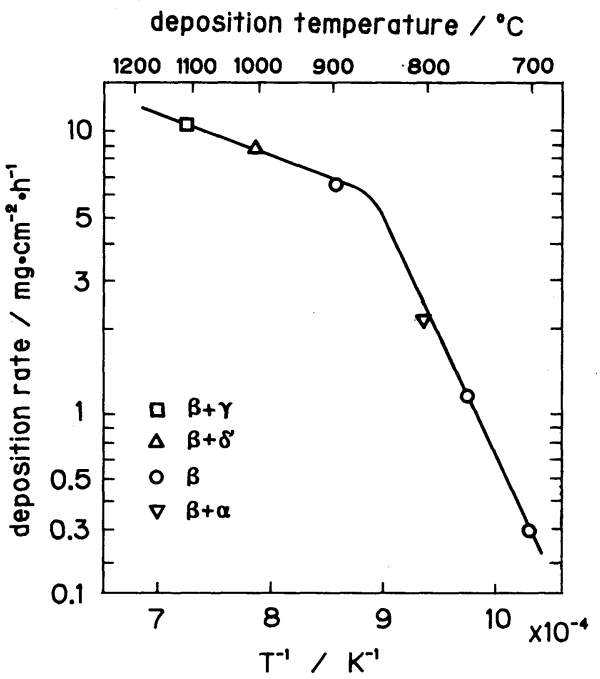

Fig. 2. Deposition rate versus deposition temperature (total gas flow rate : $4000 \mathrm{ml} / \mathrm{min}, \mathrm{N}_{2}=40 \%, \mathrm{H}_{2}=$ $20 \%, \mathrm{NbCl}_{5}=5 \times 10^{-5} \mathrm{~mol} / \mathrm{l}$, reaction time $\left.: 30 \mathrm{~min}\right)$. increased linearly with the reaction time until $2 \mathrm{~h}$ under the present experimental conditions. In Fig. 2, it is understood that the relation of deposition rate and $1 / T$ consists of two straight lines of the small gradient in higher temperature region and the large gradient in lower one.

Typical microstructures of the surface and the fractured surface of the deposits at $800^{\circ}$ and $1000^{\circ} \mathrm{C}$, which correspond to the typical two temperatures of the above two different regions, are shown in Fig. 3. The microstructure of the deposit at $800^{\circ} \mathrm{C}$ was dense, uniform and made up of fine particles. While the microstructure at $1000^{\circ} \mathrm{C}$ was characteristic of small platelike particles grown normal to the substrate. The microstructures of the deposits at two different temperatures are quite different.

The effect of total gas flow rate on the deposition rate is shown in Fig. 4 as a parameter of $\mathrm{NbCl}_{5}$ concentration: in the reactant gas at $1000^{\circ} \mathrm{C}$. As the total gas flow rate increased from 1000 to $4000 \mathrm{ml} / \mathrm{min}$, the deposition rate increased irrespective of the $\mathrm{NbCl}_{5}$ concentration. This suggests that the deposition rate is controlled by the mass transport in gas phase, and the transport of the $\mathrm{NbCl}_{5}$ vapor seems to be the ratedetermining step because the deposition rate increased with increasing the $\mathrm{NbCl}_{5}$ concentration as shown in Fig. 4. Consequently, in higher temperature region with small gradient in Fig. 2, the deposition rate is controlled by the mass transport in gas phase. In addition, the microstructure of the deposits at $1000^{\circ} \mathrm{C}$ (as shown in Fig. 3) seems to show a typical one to form in the mass transport controlled region.

The slope of the straight line in Fig. 4 was about 0.69 . This value is different from 0.5 which is the theoretical one of the slope for the mass transport controlled region ${ }^{8)}$. This difference is considered to be due to the concentration change of the reactant on the surface of the deposits with the total gas flow rate. The concentration of the reactant may decrease by homogeneous nucleation in vapor phase and/or by deposition on the wall of the reaction chamber, resulting in decrease of the deposition rate in the region of slower total gas flow rate than faster one and hence in increase of the slope of the straight line (Fig. 4).

On the other hand, in lower temperature region in Fig. 2, the gradient of the straight line is fairly larger than that of the mass transport controlled 

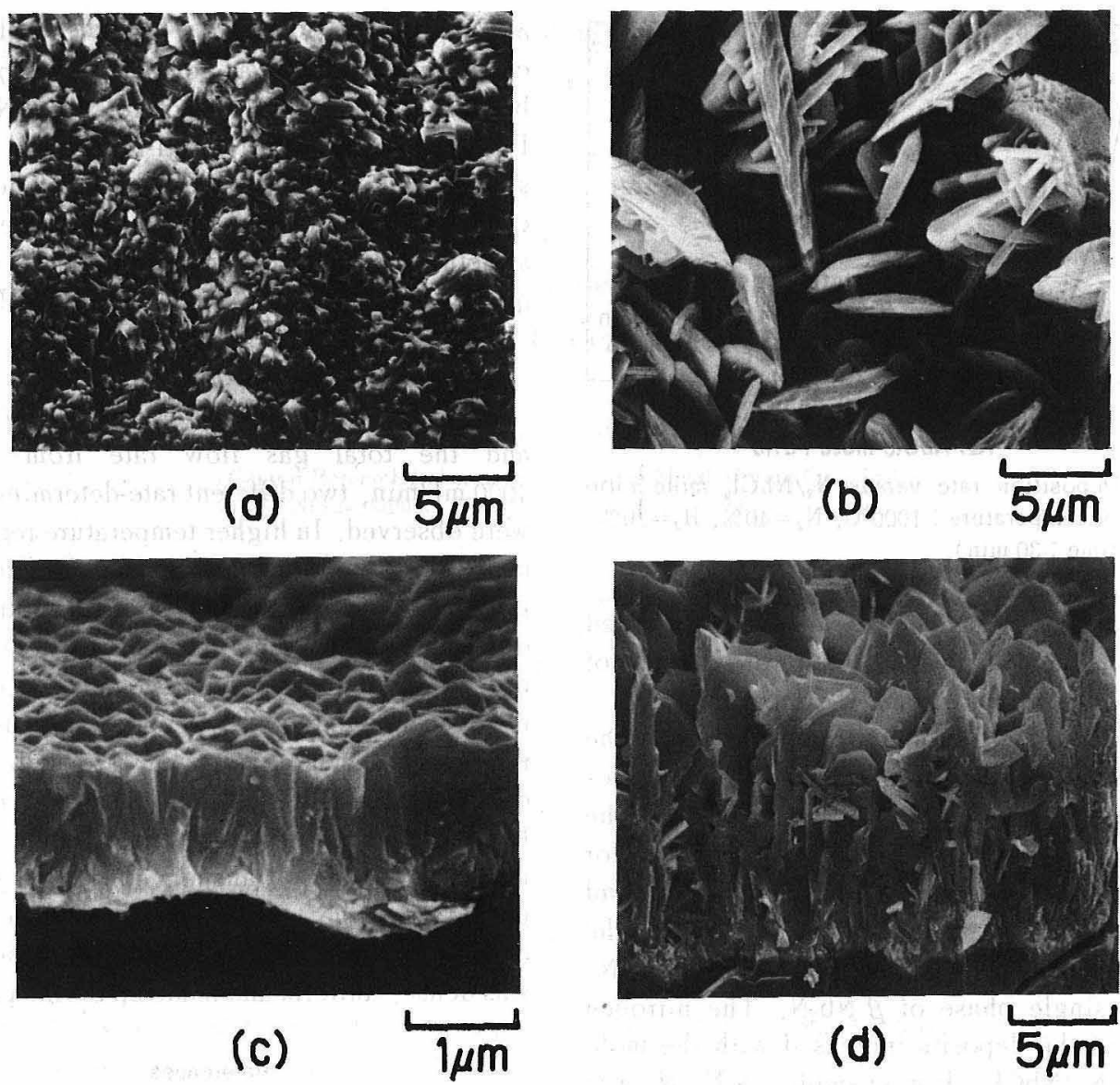

Fig. 3. Scanning electron micrographs of the deposits. Surface : (a) $800^{\circ} \mathrm{C}$, (b) $1000^{\circ} \mathrm{C}$. Fractured surface : (c) $800^{\circ} \mathrm{C}$, (d) $1000^{\circ} \mathrm{C}$ (total gas flow rate : $4000 \mathrm{ml} / \mathrm{min}, \mathrm{N}_{2}=40 \%, \mathrm{H}_{2}=20 \%, \mathrm{NbCl}_{5}=5 \times$ $10^{-5} \mathrm{~mol} / 1$, reaction time $\left.: 30 \mathrm{~min}\right)$.

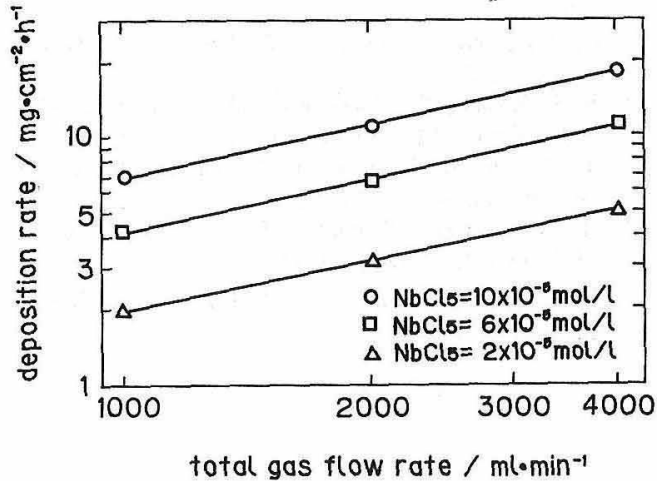

Fig. 4. Deposition rate as a function of total gas flow rate for various $\mathrm{NbCl}_{5}$ concentration (deposition temperature : $1000^{\circ} \mathrm{C}, \mathrm{N}_{2}=40 \%, \mathrm{H}_{2}=20 \%$, reaction time : $30 \mathrm{~min}$ ).

region. Hence it may be considered that the deposition rate is controlled by the surface reaction in this region. However, this result was obtained under the limited experimental con- ditions. In order to establish clearly the deposition mechanism in wider experimental conditions, it is necessary to study the relationship between the deposition rate and the other experimental parameters such as total gas flow rate, input gas composition, etc.

\subsection{Phases of deposits}

As shown in Fig. 2, the phases of the deposits were found to be strongly dependent on the deposition temperature. The phases with larger nitrogen content, i.e. $\gamma-\mathrm{Nb}_{4} \mathrm{~N}_{3}$ and $\delta^{\prime}-\mathrm{NbN}$, tended to form at higher temperature above $800^{\circ} \mathrm{C}$. However, below $800^{\circ} \mathrm{C}$, this relationship was not observed. According to Takahashi et al. ${ }^{7}$, the deposition rate depends not on the deposition temperature but on the chemical composition of the products. Nevertheless, in the present study, this relationship was not found.

The phase $\beta-\mathrm{Nb}_{2} \mathrm{~N}$ deposited above $900^{\circ} \mathrm{C}$ was grown along the $(110)$ preferred orientation. This 


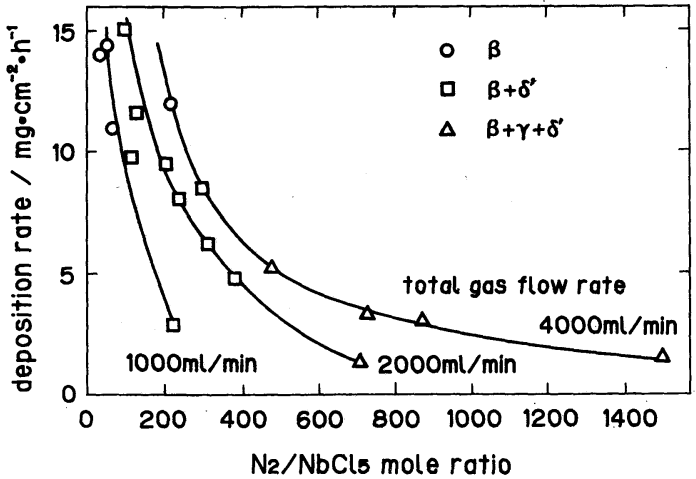

Fig. 5. Deposition rate versus $\mathrm{N}_{2} / \mathrm{NbCl}_{5}$ mole ratio (deposition temperature : $1000^{\circ} \mathrm{C}, \mathrm{N}_{2}=40 \%, \mathrm{H}_{2}=20 \%$, reaction time $: 30 \mathrm{~min}$ ).

is due to the fact that, as already mentioned above, the deposits in this region were made up of the particles grown normal to the substrate.

The effects of the mole ratio of $\mathrm{N}_{2} / \mathrm{NbCl}_{5}$ in the reactant gas on the deposition rate and the phases obtained are shown in Fig. 5 as a function of the total gas flow rate. The following three cases for combination of phases of the deposits were found : the mixed phase of $\beta-\mathrm{Nb}_{2} \mathrm{~N}$ and $\delta^{\prime}-\mathrm{NbN}$, the mixed phase of $\beta-\mathrm{Nb}_{2} \mathrm{~N}, \quad \gamma-\mathrm{Nb}_{4} \mathrm{~N}_{3}$ and $\delta^{\prime}-\mathrm{NbN}$, and the single phase of $\beta-\mathrm{Nb}_{2} \mathrm{~N}$. The nitrogen content of the deposits increased with the mole ratio of $\mathrm{N}_{2} / \mathrm{NbCl}_{5}$. For example, $\gamma-\mathrm{Nb}_{4} \mathrm{~N}_{3}$ was deposited above 400 of the mole ratio of $\mathrm{N}_{2} / \mathrm{NbCl}_{5}$. This is easily understood from the fact that $\gamma-\mathrm{Nb}_{4} \mathrm{~N}_{3}$ and $\beta-\mathrm{Nb}_{2} \mathrm{~N}$ are stable in the composition ranges of $\mathrm{NbN}_{0.70}-\mathrm{NbN}_{0.84}$ and $\mathrm{NbN}_{0.40}-\mathrm{NbN}_{0.50}$, respectively ${ }^{9}$. However, $\delta^{\prime}$ $\mathrm{NbN}$ of the composition about $\mathrm{NbN}_{0.95}$ was deposited below 400 of the mole ratio of $\mathrm{N}_{2} / \mathrm{NbCl}_{5}$. The appearance of this nitrogen-rich phase (i. e. $\delta^{\prime}-\mathrm{NbN}$ ) seems to be unreasonable at such low mole ratio of $\mathrm{N}_{2} / \mathrm{NbCl}_{5}$ where $\gamma-\mathrm{Nb}_{4} \mathrm{~N}_{3}$ disappears. However, it is possible to give an explanation for this phenomenon as follows:
$\delta^{\prime}-\mathrm{NbN}$ is considered to have a tendency to coexist with $\beta-\mathrm{Nb}_{2} \mathrm{~N}$ as compared with $\gamma-\mathrm{Nb}_{4} \mathrm{~N}_{3}$, because both crystal structures of $\beta-\mathrm{Nb}_{2} \mathrm{~N}(\varepsilon$ $\mathrm{Fe}_{2} \mathrm{~N}$ type) and $\delta^{\prime}$ - $\mathrm{NbN}$ (anti-NiAs type) are very similar and built up on the basis of hexagonal close-packed niobium atoms, but the crystal structure of $\gamma-\mathrm{Nb}_{4} \mathrm{~N}_{3}$ (distorted $\mathrm{NaCl}$ type) is quite different from $\beta-\mathrm{Nb}_{2} \mathrm{~N}$ and $\delta^{\prime}-\mathrm{NbN}$.

\section{Conclusion}

In the range of the temperature of $700^{\circ}-1100^{\circ} \mathrm{C}$ and the total gas flow rate from 1000 to $4000 \mathrm{ml} / \mathrm{min}$, two different rate-determining steps were observed. In higher temperature region, the deposition rate was controlled by the mass transport in gas phase and the microstructure of the deposits was characteristic of particles grown normal to the substrate. In this region, the nitrogen content of the deposits increased with increasing the mole ratio of $\mathrm{N}_{2} / \mathrm{NbCl}_{5}$ and the deposition temperature. On the other hand, in lower temperature region, the different mechanism from the mass transport controlled was suggested from the temperature dependence of the deposition rate. The microstructure of the deposit was dense, uniform and made up of fine particles.

\section{References}

1) L.E. Toth, "Transition Metal Carbides and Nitrides", Academic Press (1971) p. 91.

2) N. Terao, Jpn. J. Appl. Phys., 47, 2833-40 (1965)

3) N. Terao, J. Less-Common Met., 23, 159-69 (1971).

4) G. Oya and Y. Onodera, J. Appl. Phys., 10, 1485-86 (1971).

5) G. Oya and Y. Onodera, J. Vac. Sci. Technol., 7, S44-47 (1970).

6) K. S. Keskar, T. Yamashita and Y. Onodera, Jpn. J. Appl. Phys., 10, 370-74 (1971).

7) T. Takahashi, H. Itoh and T. Yamaguchi, J. Cryst. Growth, 46, 69-74 (1979).

8) H. Schlichting, "Boundary Layer Theory", 6th ed., McGraw-Hill, New York (1968).

9) N. Kieda, N. Mizutani and M. Kato, Yogyo-Kyokai-Shi, 94, 73-77 (1986). 